\title{
Effect of different photoperiods on testicular weight changes in the vole, Microtus agrestis
}

\author{
C. Anne Grocock \\ Department of Human Anatomy, South Parks Road, Oxford OX1 3QX, U.K.
}

\begin{abstract}
Summary. The testicular weight response of 2-week-old male voles exposed to 10 , $12,14,15$ or $16 \mathrm{~h}$ light (L) per day for 4 weeks and of 5-week-old males exposed from birth to $12,13,13 \cdot 5,14,14 \cdot 25,14 \cdot 5,14 \cdot 75$, or $15 \mathrm{~h}$ light per day was proportional to the photoperiod: $13 \mathrm{~L}$ or less produced little growth but $13.5 \mathrm{~L}$ or more produced progressively heavier testes. Only $14.5 \mathrm{~L}$ and $15 \mathrm{~L}$ gave full spermatogenesis. 'Night-break' schedules produced a marked testicular response with $7 \mathrm{~L}: 8 \mathrm{D}: 1 \mathrm{~L}: 8 \mathrm{D}$ and $7 \mathrm{~L}: 6 \mathrm{D}: 1 \mathrm{~L}: 10 \mathrm{D}$, intermediate effects with $7 \mathrm{~L}: 4 \mathrm{D}: 1 \mathrm{~L}: 12 \mathrm{D}$ and none with $7 \mathrm{~L}: 2 \mathrm{D}: 1 \mathrm{~L}: 14 \mathrm{D}$. Of various skeleton photoperiods with $0.75 \mathrm{~L}$ only $0.75 \mathrm{~L}: 12.5 \mathrm{D}: 0.75 \mathrm{~L}: 10 \mathrm{D}$ and $0.75 \mathrm{~L}: 10.5 \mathrm{D}: 0.75 \mathrm{~L}: 12 \mathrm{D}$ produced marked increases in testicular weight. The peak of photosensitivity appeared to be phase-shifted towards 'dawn' by reducing the initial light phase. Its position appeared to move from $16 \mathrm{~h}$ after 'dawn' in block photoperiods to $14 \mathrm{~h}$ after 'dawn' in the 'night-break' and $12 \mathrm{~h}$ after 'dawn' in the skeleton photoperiod experiments.

Previous experience of $16 \mathrm{~L}: 8 \mathrm{D}$ or $8 \mathrm{~L}: 16 \mathrm{D}$ had little effect on the subsequent response to skeleton photoperiods $(0.5 \mathrm{~L}: 9 \mathrm{D}: 0.5 \mathrm{~L}: 14 \mathrm{D}, 0.5 \mathrm{~L}: 13 \mathrm{D}: 0.5 \mathrm{~L}: 10 \mathrm{D}$, $0 \cdot 5 \mathrm{~L}: 15 \mathrm{D}: 0.5 \mathrm{~L}: 8 \mathrm{D})$. Animals reared in these photoperiods only showed a positive testicular response to $0.5 \mathrm{~L}: 13 \mathrm{D}: 0 \cdot 5 \mathrm{~L}: 10 \mathrm{D}$. The lack of response to constant darkness indicated that voles were capable of perceiving these skeleton photoperiods.
\end{abstract}

\section{Introduction}

Photoperiod is an important factor regulating reproductive activity in voles (Baker \& Ranson, 1932; Clarke \& Kennedy, 1967; Grocock \& Clarke, 1974) as in a number of other mammals (Elliott, Stetson \& Menaker, 1972; Lincoln \& Davidson, 1977; Turek \& Campbell, 1979) and birds (Menaker, 1965; Farner \& Follett, 1966; Follett, 1973; Gwinner, 1973). Reproductive activity in 'long-day' animals can be stimulated by a long light period (e.g. $16 \mathrm{~h}$ ) followed by a shorter dark period (e.g. 8 h). However, the photoperiodic response does not require the light phase to be continuous for $16 \mathrm{~h}$ since interrupting the long dark period of a short day with an appropriately placed short pulse of light will be sufficient to mimic the effects of a long day. This type of 'night-break' experiment has been used for some time in work on plant photoperiodism (Bünning, 1960) and has been shown to be effective in vertebrates, particularly birds (Farner, 1965; Menaker, 1965; Lofts \& Lam, 1973; Follett, 1973; Hoffmann, 1979). 'Night-break' experiments provide some evidence for the existence of internal circadian oscillators which may be involved in the photoperiodic response. The coincidence model suggests that when light coincides with an internal circadian rhythm of photosensitivity a positive response occurs 
(Pittendrigh \& Minis, 1964). Pittendrigh \& Daan (1976) have suggested that there are in fact two circadian oscillators which mutually interact but which are coupled separately to sunrise and sunset, thus allowing the oscillators to accommodate for seasonal changes in daylength.

Resonance experiments may provide better evidence for the existence of circadian oscillators (Follett, 1973; Follett \& Davies, 1975). In this type of experiment a short photoperiod (6 or $8 \mathrm{~h}$ ) is combined with various lengths of dark periods up to $66 \mathrm{~h}$. Although the light only coincides with the photosensitive phase(s) every few days, this is sufficient to simulate the effects of long days (Hamner, 1963; Follett \& Sharp, 1969; Elliott et al., 1972).

Voles have been tested in resonance experiments (Grocock \& Clarke, 1974) but a number of photoperiodic effects remain to be investigated, particularly with respect to the response of the animal in the field to natural daylength. Firstly, the possibility arose that there is a 'threshold' photoperiod or critical daylength above which all daylengths are stimulatory and below which they are inhibitory in terms of reproductive activity (Breed \& Clarke, 1970). Secondly, a 'night-break' experiment would determine whether the vole can respond to a short pulse of light in the dark period of a short day. Thirdly, the 'night-break' experiment can be modified to produce a symmetrical skeleton photoperiod in which the initial 6 or $8 \mathrm{~h}$ photoperiod is reduced to the same length as the 'night-break' pulse to test whether the circadian oscillator(s) can still respond. This latter type of experiment may have relevance to the activity pattern of voles in the wild. Furthermore, the effects of previous experience may also be important in a subsequent response to any natural or artificial photoperiod.

\section{Materials and Methods}

Male voles from the colony in the Department of Human Anatomy were used. Animals were housed 3-6 to a cage after weaning. Guinea pig diet (RGP: Dixons) and water were always available. Peat moss, hay and cotton wool were provided for bedding. Photoperiods of $16 \mathrm{~h}$ light and $8 \mathrm{~h}$ dark $(16 \mathrm{~L}: 8 \mathrm{D})$ or $8 \mathrm{~h}$ light and $16 \mathrm{~h}$ dark $(8 \mathrm{~L}: 16 \mathrm{D})$ were provided in the animal house rooms by means of fluorescent tubes controlled by time clocks. Other photoperiods were set up in light boxes illuminated by fluorescent tubes and controlled by time clocks with specially designed electronic devices to give accurately timed short periods of light (e.g. $30 \mathrm{~min}$ ). All photoperiods had the same time for lights on $(09: 00 \mathrm{~h})$ which is subsequently referred to as 'dawn'. The patterns used are shown in Text-fig. 1.

\section{Experiment 1: critical daylength}

In Exp. 1A, male voles were raised in $16 \mathrm{~L}: 8 \mathrm{D}$ and, at 2 weeks of age, 53 were transferred to 10L:14D, 12L:12D, 14L:10D, 15L :9D or kept in 16L:8D for 4 weeks. In Exp. 1B, the males (a total of 76) were born into a photoperiod of $12,13,13 \cdot 5,14,14 \cdot 25,14 \cdot 5,14 \cdot 75$ or $15 \mathrm{~h}$ light per $24 \mathrm{~h}$ and were killed 5 weeks later.

\section{Experiment 2: $1 \mathrm{~h}$ 'night-break' experiment}

A total of 76 males raised in $16 \mathrm{~L}: 8 \mathrm{D}$ were exposed, at 2 weeks of age, to $8 \mathrm{~L}: 16 \mathrm{D}$, 7L :2D :1L:14D, 7L :4D :1L:12D, 7L:6D :1L :10D, 7L:8D :1L:8D or 16L :8D for 4 weeks.

\section{Experiment 3: skeleton photoperiods}

In Exp. $3 \mathrm{~A}$ both the initial photoperiod and the second 'pulse' were reduced to $45 \mathrm{~min}$ $(0.75 \mathrm{~L})$ light per day. The 99 males were raised in $16 \mathrm{~L}: 8 \mathrm{D}$ and at 2 weeks of age were 
exposed for 4 weeks to $0.75 \mathrm{~L}: 6.5 \mathrm{D}: 0.75 \mathrm{~L}: 16 \mathrm{D}, \quad 0.75 \mathrm{~L}: 8.5 \mathrm{D}: 0.75 \mathrm{~L}: 14 \mathrm{D}$, $0.75 \mathrm{~L}: 10 \cdot 5 \mathrm{D}: 0.75 \mathrm{~L}: 12 \mathrm{D}, 0.75 \mathrm{~L}: 12 \cdot 5 \mathrm{D}: 0.75 \mathrm{~L}: 10 \mathrm{D}$ or $0.75 \mathrm{~L}: 14.5 \mathrm{D}: 0.75 \mathrm{~L}: 8 \mathrm{D}$.

In Exp. 3B, the light 'pulse' was reduced to $30 \mathrm{~min}(0.5 \mathrm{~L})$ and the photoperiods used were $0.5 \mathrm{~L}: 9 \mathrm{D}: 0.5 \mathrm{~L}: 14 \mathrm{D}, 0.5 \mathrm{~L}: 13 \mathrm{D}: 0.5 \mathrm{~L}: 10 \mathrm{D}$ or $0.5 \mathrm{~L}: 15 \mathrm{D}: 0.5 \mathrm{~L}: 8 \mathrm{D}$. In Group (i) the 36 males were raised in $16 \mathrm{~L}: 8 \mathrm{D}$ for 2 weeks before being transferred to one of the 3 photoperiods for 4 weeks. In Group (ii) the 42 males were raised in $8 \mathrm{~L}: 16 \mathrm{D}$ before transfer and in Group (iii) the 25 males were born into the photoperiods being tested. All animals were killed at 6 weeks of age. For comparison, Group (iv) consisted of 4 males raised in $16 \mathrm{~L}: 8 \mathrm{D}$ and transferred at 2 weeks of age to constant dark (DD) for 4 weeks, while Group (v) consisted of 3 males born and maintained in DD until 6 weeks old.

At the end of all experiments the animals were weighed and killed and the testes were removed and weighed. The testes were processed for routine light microscopy by fixation in Bouin's fluid, embedding in paraffin wax, sectioning at $5 \mu \mathrm{m}$ and staining with haematoxylin and eosin.

Statistical analyses were carried out to determine differences between treatments. Analysis of variance (ANOVA) was used to detect overall treatment differences and differences between treatment means were tested using Duncan's multiple range test (MRT). When $t$ tests were also used this has been indicated in the text.

\section{Results}

\section{Experiment 1: critical daylength}

Photoperiods of $13 \mathrm{~h}$ or less prevented any significant testicular growth (Text-fig. 2). Photoperiods of $13.5 \mathrm{~h}$ or longer stimulated testicular growth but the amount of growth was proportional to the photoperiod. The testes of males of 5 weeks of age and exposed to $14 \mathrm{~h}$ light $/ 24 \mathrm{~h}$ were significantly larger than those of males given $13 \mathrm{~h}$ or less $(P<0.01$ by ANOVA and MRT) but significantly smaller $(P<0.01 \mathrm{MRT})$ than those of males given $15 \mathrm{~h}$ light $/ 24 \mathrm{~h}$. At 6 weeks of age, the testes of males exposed to $14 \mathrm{~h}$ light $/ 24 \mathrm{~h}$ were significantly heavier than those of males given $12 \mathrm{~h}$ or less $(P<0.02$ by $t$ test only) but significantly smaller $(P<0.01$ and $P<0.05$ by ANOVA and MRT respectively) than those of males given 15 or $16 \mathrm{~h} \mathrm{light} / 24 \mathrm{~h}$.

\section{Experiment 2: 'night-break'}

When the $1 \mathrm{~h}$ light pulse was positioned 6 or $8 \mathrm{~h}$ after the end of the initial 7 -h photoperiod then the testicular response was the same as in a long photoperiod $16 \mathrm{~L}: 8 \mathrm{D}$ (Text-fig. 2). If the $1 \mathrm{~h}$ pulse was placed $2 \mathrm{~h}$ after the 7-h photoperiod then the testicular response was the same as in 8L:16D (all 'long' day treatments, i.e. Groups d, e and f, were different from 'short' day treatments, i.e. Groups a and b, $P<0.01$, ANOVA and $P<0.001 \mathrm{MRT}$ ). When the light pulse was positioned $4 \mathrm{~h}$ after the initial $7 \mathrm{~h}$ photoperiod the response was intermediate and different $(P<0.05 \mathrm{MRT})$, from 'long' and 'short' day responses.

\section{Experiment 3: skeleton photoperiods}

In Exps $3 \mathrm{~A}$ and $3 \mathrm{~B}(\mathrm{i})-(\mathrm{iii})$ a total of 1.5 or $1 \mathrm{~h}$ of light was given per day. In Exp. 3A the change in testicular weight (Text-fig. 2) was similar to that in Exps 1 and 2 but the increase occurred at $12 \mathrm{~h}$ rather than 14 or $16 \mathrm{~h}$ after 'dawn.'

When the two light pulses were separated by 12.5 or $10.5 \mathrm{~h}$ the testes were significantly heavier than when the light pulses were separated by $14.5 \mathrm{~h}(P<0.01$ and $P<0.05$ by ANOVA and MRT respectively) or by 8.5 or $6.5 \mathrm{~h}$ of darkness $(P<0.01$ by ANOVA and 


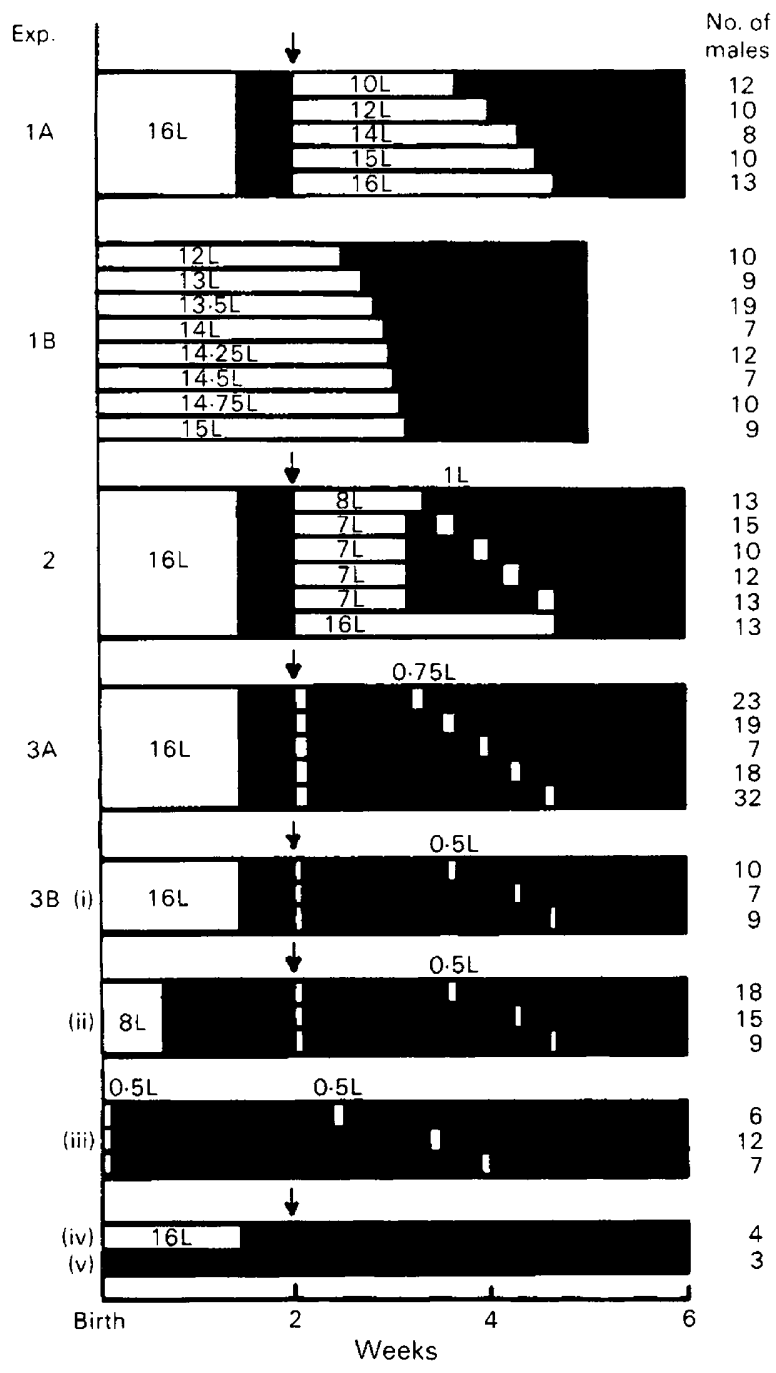

Text-fig. 1. Experimental design of the various photoperiods used. Each block shows the L:D ratio given daily and the duration of treatment. In Exps 1B, 3B (iii) and (v) animals were exposed to the appropriate photoperiods from birth. The numbers of animals in each group are indicated. The arrow indicates the change of photoperiod.

MRT). The testicular weights for animals born in 16L:8D (Exp. 3B(i), Text-fig. 2) and given $1 \mathrm{~h}$ light/day were not significantly different from those for animals given $1.5 \mathrm{~h}$ light per day (Exp. 3A, Text-fig. 2). Although there was an increase in testicular weight in Group 3B(i) animals when the light pulses were placed $13 \mathrm{~h}$ apart compared with 9 or $15 \mathrm{~h}$, the differences were only just statistically significant $(P<0.05$ only when using $t$ tests and not ANOVA and MRT).

The results for Group 3B(ii) animals were similar to those of Group 3B(i) except that testicular weight in $0.5 \mathrm{~L}: 13 \mathrm{D}: 0.5 \mathrm{~L}: 10 \mathrm{D}$ was significantly less $(P<0.05$ with $t$ test only).

Differences in the testicular response to the three photoperiods (Text-fig. 2) were more marked in animals in Group 3B(iii), with those torn into $0.5 \mathrm{~L}: 13 \mathrm{D}: 0.5 \mathrm{~L}: 10 \mathrm{D}$ having significantly larger testes $(P<0.01$, ANOVA; $P<0.02, t$ test $)$. Testicular weights in $0.5 \mathrm{~L}: 15 \mathrm{D}: 0.5 \mathrm{~L}: 8 \mathrm{D}$ and $0.5 \mathrm{~L}: 9 \mathrm{D}: 0.5 \mathrm{~L}: 14 \mathrm{D}$ in Group $3 \mathrm{~B}$ (iii) were not significantly different 


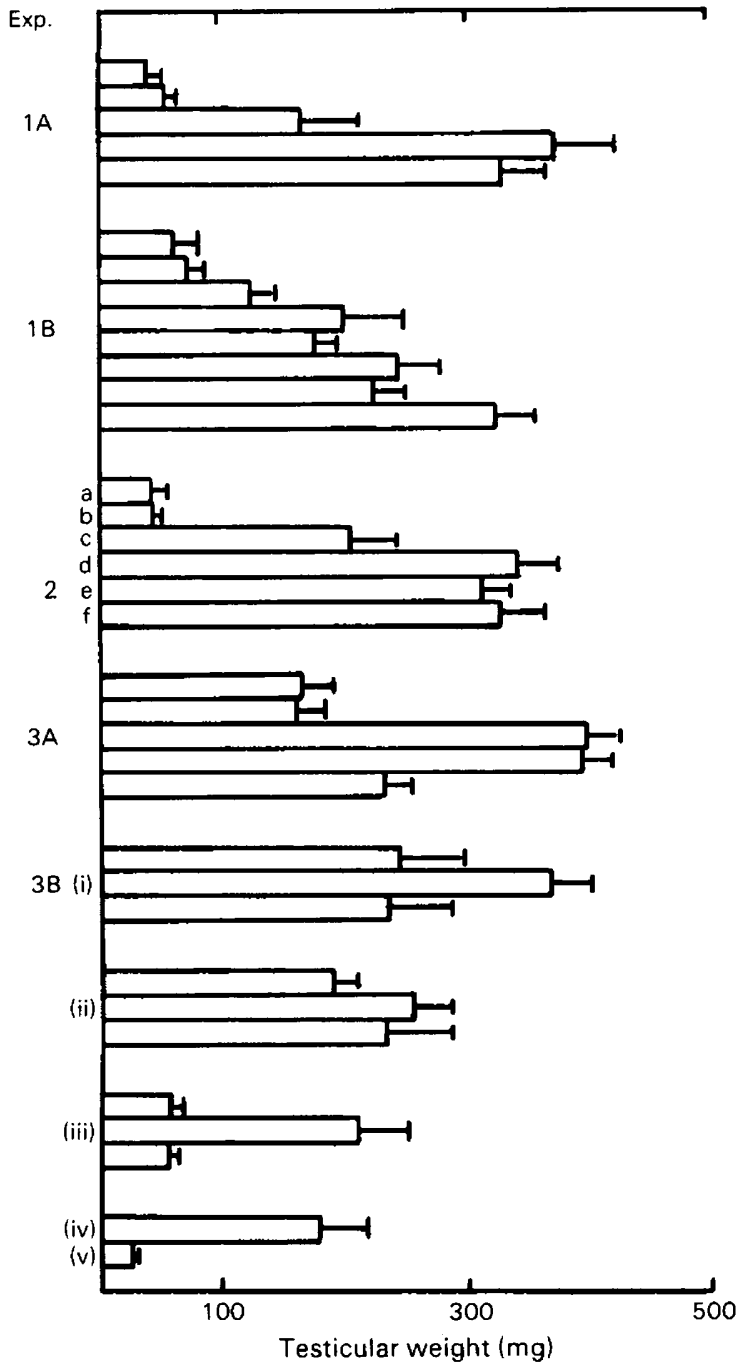

Text-fig. 2. Mean ( \pm s.e.m.) testicular weights of males voles subjected to the various photoperiods shown in Text-fig. 1.

from each other, but were less than those for animals in Groups 3B(i) and 3B(ii) $(P<0.02$ for $0.5 \mathrm{~L}: 9 \mathrm{D}: 0.5 \mathrm{~L}: 14 \mathrm{D}$ treatment, and $P<0.02$ for $0.5 \mathrm{~L}: 15 \mathrm{D}: 0.5 \mathrm{~L}: 8 \mathrm{D}$ treatment by $t$ tests only).

The testicular weights of animals in Groups $3 \mathrm{~B}$ (iv) $(180 \pm 37.4 \mathrm{mg}, \mathrm{N}=4)$ and $3 \mathrm{~B}(\mathrm{v})(28 \cdot 1$ $\pm 3.4 \mathrm{mg}, \mathrm{N}=3)(P<0.02, t$ test $)$ show that previous experience of $16 \mathrm{~L}: 8 \mathrm{D}$ allows the testes to grow. It is therefore possible that some of the animals in Exp. 3B (i)-(iii) did not perceive the two short light pulses and were effectively experiencing constant darkness. However, results for animals in Group 3B(iii) which were born into $0.5 \mathrm{~L}: 13 \mathrm{D}: 0.5 \mathrm{~L}: 10 \mathrm{D}$ and had a mean testicular weight of $210 \mathrm{mg}$ suggests that this is unlikely.

\section{Testicular histology}

In general, testes heavier than $200 \mathrm{mg}$ had full spermatogenesis whereas those $<200 \mathrm{mg}$ had variable degrees of spermatogenic development from tubules containing only spermatogonia and 
Sertoli cells to those containing large numbers of germ cells but not mature spermatozoa. With long days of $>14.5 \mathrm{~h}$ most animals had full spermatogenesis. In Exp. 2 only animals in $7 \mathrm{~L}: 2 \mathrm{D}: 1 \mathrm{~L}: 14 \mathrm{D}, 8 \mathrm{~L}: 16 \mathrm{D}$ and 4 out of 10 animals in $7 \mathrm{~L}: 4 \mathrm{D}: 1 \mathrm{~L}: 12 \mathrm{D}$ did not show full spermatogenesis. In Exp. 3 animals with testicular weights $>200 \mathrm{mg}$ again showed full spermatogenesis whereas those with testes $<200 \mathrm{mg}$ did not.

\section{Discussion}

Previous experiments on the effects of photoperiod on ovarian function (Breed \& Clarke, 1970) indicated that there was a 'threshold' photoperiod of between 12 and $14 \mathrm{~h}$ light per day, with photoperiods of $14 \mathrm{~h}$ or longer stimulating and those of $12 \mathrm{~h}$ or less inhibiting gonadal development. Results from the present experiments indicate that $13 \mathrm{~h}$ of light may be the 'critical' daylength but in photoperiods longer than this testicular growth is proportional to the length of the photoperiod. Similar results have been obtained for the Japanese quail (Follett \& Maung, 1978). In the present experiments it was only when the photoperiod was $14.5 \mathrm{~h}$ or longer that full spermatogenesis was observed in 5- and 6-week-old males. In male voles born and maintained in long days of $16 \mathrm{~L}$, spermatozoa first appear in the testes at 5 weeks of age but full fertility is not achieved until 6 weeks of age (Grocock, 1979).

The 'night-break' experiment (Exp. 2) indicated that, as in other species (Follett \& Sharp, 1969; Murton, Lofts \& Westwood, 1970; Lofts \& Lam, 1973; Hoffmann, 1979), a short photoperiod, in this case $1 \mathrm{~h}$ of light, placed appropriately in the dark period after a short day, in this case $7 \mathrm{~h}$, can induce testicular development (Text-fig. 2). An increase in testicular weight was seen when the light pulse was given $12 \mathrm{~h}$ after 'dawn' (7L:4D:1L:12D) but if the pulse was given $14 \mathrm{~h}$ after 'dawn' (7L:6D :1L:10D) testicular weight was considerably heavier $(>300 \mathrm{mg}$ ) than in males kept in $14 \mathrm{~L}: 10 \mathrm{D}$ and comparable to those of males in $15 \mathrm{~L}: 9 \mathrm{D}$ or $16 \mathrm{~L}: 8 \mathrm{D}$. Similar effects were observed in the skeleton photoperiod experiments when the dark period was illuminated 12 or $14 \mathrm{~h}$ after 'dawn'; testicular weights were $>400 \mathrm{mg}$ (Text-fig. 2). Illumination of the dark period $12 \mathrm{~h}$ after 'dawn' $(0.75 \mathrm{~L}: 10 \cdot 5 \mathrm{D}: 0.75 \mathrm{~L}: 12 \mathrm{D})$ produced heavier testes than the equivalent 'night-break' $7 \mathrm{~L}: 4 \mathrm{D}: 1 \mathrm{~L}: 12 \mathrm{D}$ or $12 \mathrm{~L}: 12 \mathrm{D}$ photoperiod. It would therefore appear that with a continuous block of light the peak of photosensitivity occurs about $16 \mathrm{~h}$ after dawn. Reducing the initial photoperiod to $7 \mathrm{~h}$ and introducing a $1 \mathrm{~h}$ 'night-break' moves the peak towards $14 \mathrm{~h}$ after 'dawn'. A further reduction in the photoperiod to two 45 -min periods moves the peak of photosensitivity nearer to $12 \mathrm{~h}$ after 'dawn'. Such effects have also been observed in the Japanese quail (Follett \& Sharp, 1969) in which initial photoperiods of 3,6 or $9 \mathrm{~h}$ followed by 15 -min pulses of light caused an advancement of the photosensitive phase as the duration of the main photoperiod was decreased. The duration of the phase was, however, similar in all cases. This shifting of the photosensitive phase has also been observed under natural conditions in tree sparrows (Lofts \& Lam, 1973), in which phase-shifting of the photosensitive peak occurred in the winter so that the phase did not coincide with the winter photoperiod of $11 \mathrm{~h}$.

Phase-shifting in the peak of photosensitivity is not the only explanation for the difference in testicular weights of animals exposed to $7 \mathrm{~L}: 6 \mathrm{D}: 1 \mathrm{~L}: 10 \mathrm{D}$ and $14 \mathrm{~L}: 10 \mathrm{D}$ (Exps 1 and 2). It has been observed (Follett \& Sharp, 1969) that in some 'night-break' experiments the shorter light pulse may be read as 'dawn'. If this were so in the present experiments then $7 \mathrm{~L}: 6 \mathrm{D}: 1 \mathrm{~L}: 10 \mathrm{D}$ could be considered equivalent to $18 \mathrm{~L}: 6 \mathrm{D}$. Similar problems arise in the interpretation of the data from experiments using two symmetrical short pulses of light, 30 or $45 \mathrm{~min}$ (Exps $3 \mathrm{~A}$ and $3 \mathrm{~B})$, because it is not clear which of the two light pulses is treated as 'dawn'.

Comparisons of the effects of previous photoperiod experience on the testicular response to two 30-min light pulses indicated that rearing the animals for 2 weeks in long or short days did not, at least in two of the light schedules, significantly alter the testicular response (Text-fig. 2). 
When the two light pulses were most nearly equally spaced $(0 \cdot 5 \mathrm{~L}: 13 \mathrm{D}: 0 \cdot 5 \mathrm{~L}: 10 \mathrm{D})$, animals raised in long days (16L:8D) had a significantly greater testicular weight than those reared in short days and no significant change in testicular weights was seen in voles raised on short days (8L: 16D). However, animals born into the light schedules showed a significant increase in testicular weight when the dark phase was illuminated $14 \mathrm{~h}$ after 'dawn', thus indicating that prior entrainment to a long or short day is not required to produce a positive response to a skeleton photoperiod.

Voles in the laboratory therefore appear to be capable of responding to very short periods of light, but the question remains as to whether this mechanism is used by animals in the field. The natural habitat of voles is grassland where they live in underground burrows and surface regularly to feed. Thus they are not exposed to continuous illumination during the daytime. It seems likely that, since voles are most active at dawn and dusk, a positive testicular response will occur if light is only coincident with the photosensitive phase at either or both of these times. What remains to be shown is whether in the vole, as in the tree sparrow, the photosensitive phase is shifted according to the time of year.

I thank Miss S. Collins, Mr G. Ferrick and Mr P. Pledge for technical assistance, and Mr R. Underwood for devising and making the photoperiod equipment. The research was supported by grants from the Medical Research Council and the Agricultural Research Council.

\section{References}

Baker J.R. \& Ranson, R.M. (1932) Factors affecting the breeding of the field mouse (Microtus agrestis). Part 1. Light. Proc. R. Soc. B 110, 313-322.

Breed, W.G. \& Clarke, J.R. (1970) Effect of photoperiod on ovarian function in the vole, Microtus agrestis. $J$. Reprod. Fert. 23, 189-192.

Bünning, E. (1960) Circadian rhythms and time measurement in photoperiodism. Cold Spring Harbor Symp. quant. Biol. 25, 249-256.

Clarke, J.R. \& Kennedy, J.P. (1967) Effect of light and temperature upon gonad activity in the vole (Microtus agrestis). Gen. comp. Endocr. 8, 474-488.

Elliott, J.A., Stetson, M.H. \& Menaker, M. (1972) Regulation of testis function in golden hamsters: a circadian clock measures photoperiodic time. Science, N.Y. 178, 771-773.

Farner, D.S. (1965) Circadian systems in the photoperiodic responses of vertebrates. In Circadian Clocks, pp. 357-369. Ed. J. Aschoff. NorthHolland, Amsterdam.

Farner, D.S. \& Follett, B.K. (1966) Light and other environmental factors affecting avian reproduction. J. Anim. Sci. 25, Suppl. 90-118.

Follett, B.K. (1973) Circadian rhythms and photoperiodic time-measurement in birds. J. Reprod. Fert., Suppl. 19, 5-18.

Follett, B.K. \& Davies, D.T. (1975) Photoperiodicity and the neuroendocrine control of reproduction in birds. Symp. Zool. Soc. Lond. 35, 188-224.

Follett, B.K. \& Maung, S.L. (1978) Rate of testicular maturation, in relation to gonadotrophin and testosterone levels, in quail exposed to various artificial photoperiods and to natural daylengths. J. Endocr. $78,267-280$.
Follett, B.K. \& Sharp, P.J. (1969) Circadian rhythmicity in photoperiodically induced gonadotrophin release and gonadal growth in the quail. Nature, Lond. 223, 968-971.

Grocock, C.A. (1979) Testis development in the vole, Microtus agrestis, subjected to long or short photoperiods from birth. J. Reprod. Fert. 55, 423-427.

Grocock, C.A. \& Clarke, J.R. (1974) Photoperiodic control of testis activity in the vole, Microtus agrestis. J. Reprod. Fert. 39, 337-347.

Gwinner, E. (1973) Circannual rhythms in birds: their interaction with circadian rhythms and environmental photoperiod. J. Reprod. Fert., Suppl. 19, 51-65.

Hamner, W.M. (1963) Diurnal rhythm and photoperiodism in testicular recrudescence of the house finch. Science, N.Y. 142, 1294-1295.

Hoffmann, K. (1979) Photoperiodic effects in the Djungarian hamster: one minute of light during darktime mimics influence of long photoperiods on testicular recrudescence, body weight and pelage colour. Experientia 35, 1529-1530.

Lincoln, G.A. \& Davidson, W. (1977) The relationship between sexual and aggressive behaviour, and pituitary and testicular activity during the seasonal sexual cycle of rams, and the influence of photoperiod. J. Reprod. Fert. 49, 267-276.

Lofts, B. \& Lam, W.L. (1973) Circadian regulation of gonadotrophin secretion. J. Reprod. Fert., Suppl. 19, 19-34.

Menaker, M. (1965) Circadian rhythms and photoperiodism in Passer domesticus. In Circadian Clocks, pp. 385-395. Ed. J. Aschoff. North-Holland, Amsterdam. 
Murton, R.K., Lofts, B. \& Westwood, N.J. (1970) The circadian basis of photoperiodically controlled spermatogenesis in the greenfinch, Chloris chloris. J. Zool., Lond. 161, 125-136.

Pittendrigh, C.S. \& Daan, S. (1976) A functional analysis of circadian pacemakers in nocturnal rodents. V. Pacemaker structure: a clock for all seasons. J. comp. Physiol. 106, 333-355.
Pittendrigh, C.S. \& Minis, D.H. (1964) The entrainment of circadian oscillations by light and their role as photoperiodic clocks. Am. Nat. 98, 261-294.

Turek, F.W. \& Campbell, C.S. (1979) Photoperiodic regulation of neuro-endocrine-gonadal activity. Biol. Reprod. 20, 32-50.

Received 4 June 1980 